\title{
Library Consortia in Developing Countries: An Overview
}

\author{
by \\ Golnessa Galyani Moghaddam \\ Department of Library and Information Science, Shahed University, \\ Tehran, Iran, and \\ V.G. Talawar \\ Department of Library and Information Science, University of Mysore, \\ Mysore, India
}

\begin{abstract}
:
"Library consortia" refers to co-operation, co-ordination and collaboration between, and among, libraries for the purpose of sharing information resources. The purpose of this paper is to review consortia efforts in developing countries. The paper reviews the literature on library consortia in developing countries in general and India in particular. It also outlines the advantages and disadvantages of consortia. The literature review reveals that libraries in developing countries have been working on consortia at national, regional and international level. However, some barriers such as poor technological and communication infrastructure, inadequate finances, culture and context, attitudes toward consortia and multiple efforts are reported to be limitations of consortia activities in developing countries.
\end{abstract}

Keywords: Developing countries, India, Libraries, Services, Purchasing groups, Knowledge sharing

\section{Introduction}

Libraries today are facing increasing demands for services while struggling with the challenges such as the rise in the information resources, high cost of library materials, high expectations from users, budget cuts and much more. Library consortia are created to help libraries obtain better prices by buying joint access for a greater number of users, expanding access to print and electronic collections and developing new services to meet their customers' needs. This paper attempts to address a short historic view of library consortia, the advantages and disadvantages of consortia for libraries, consortia activities in developing countries in general and in India in particular. The purpose is to give a picture of current trends regarding consortia in developing countries.

"Library consortia" refers to the co-operation, co-ordination and collaboration between and among libraries for the purpose of sharing information resources. A review of the literature shows that "library consortia" is not a new concept. Early examples, from the late 1960s include the development of the Ohio College Libraries Center (OCLC) as a regional computer system for 54 Ohio college libraries to share their resources and to reduce costs, and the Birmingham Libraries Co-operative Mechanisation Project (BLCMP) in the UK. However consortia were not really common until the 1980s. The main driving forces for collaboration among libraries, especially academic libraries, has been the increase in numbers of publications and the rise in the cost of publications as well as the decline in library budgets. The increase in student enrolment in higher education and increasing demands for 
library services and collections were other factors given, from the 1980s onwards, for collaborative efforts by Nfila and Darko-Ampem (2002).

Historically, the common form of library co-operation was the sharing of union catalogue information, storage facilities, collection development and human resources at local, national and regional levels in the US (Payne, 1998). Later, other countries also ventured into co-operative efforts. In the period between 1980 and 1990 many libraries in Western countries were involved with library automation, coupled with the increased use of computers in bibliographic processing activities and database searching. There was a need to share expertise on library automation and this was considered as a possible reason to move toward library consortia in the 1980s by Nfila and Darko-Ampem (2002).

The development of the web in the 1990s imposed new challenges for libraries. In the print era, libraries used to buy a resource and own it. Copyright law allowed for fair use in ways that advanced education, study and scholarship. In the digital era however, use of information resources comes under contract law as libraries acquire licences to use the material. Libraries become involved in several partnerships when a licence is created. Electronic publishing also brought many possibilities for resource sharing and consortial activities have increased with advances in ICT. Co-operative and collaborative efforts have grown from being on the periphery with a limited amount of resource sharing to being an integrated system-wide resource sharing in recent years in the West. The International Coalition of Library Consortia (ICOLC: www.library.yale.edu/consortia/icolcmembers.html) is an informal group of some 150 library consortia from around the world. Examples of consortia from North America include:

- Academic Libraries of Indiana (ALI: http://ali.bsu.edu/).

- Boston Libraries Consortium (BLC: www.blc.org/).

- Ontario Library Consortium (OLC: www.onlibcon.on.ca/).

- Washington Research Library Consortium (WRLC: www.wrlc.org/).

\section{Advantages and disadvantages of library consortia}

\subsection{Advantages}

The advantages for libraries if they buy their resources through consortia can include:

- $\quad$ shared access to information sources;

- $\quad$ sitewide access for all involved;

- smaller libraries can benefit;

- possible global impact;

- common interface to resources;

- possible ability to attract foreign investment; and

- $\quad$ ability to achieve goals.

Consortia can bring economy, efficiency and equality in information availability and use. Participant institutions in a consortium have access not only to their own resources but sources in the other institutions as well. 
This can allow the gap between information resource rich libraries and those, which are resource deficient to be bridged (Pandian et al., 2002).

Libraries can acquire more resources by paying less if they are members of a consortia. Consortia purchasing offers, for the single library, the opportunity to gain access to more resources than might otherwise be possible. For the consortia members it offers reduced costs in the inter-institutional document delivery processes for specific resources.

Resource sharing is considered to be a great advantage of consortia for libraries, as today, the ability for users to access resources is often more important than collection building within a particular library. Through a library consortium, the collective strength of resources of various institutions available to it can be increased. The consortia enables libraries to gain the benefits of wider access to electronic resources at an affordable cost (Singh and Singh, 2004).

\subsection{Disadvantages}

Helmer (2004), of the Orbis Cascade Alliance in the Northwest of the US, listed the following disadvantages of consortia:

- duplication of effort;

- $\quad$ reduced buying power;

- confusion for libraries, vendors, and patrons;

- diffusion of financial resources; and

- diffusion of human resources.

The disadvantages mentioned in the previous list of library consortia are recognised in Western countries particularly in the US. The same would apply to libraries in the developing countries that are trying to buy their collections through consortia. Of course, other problems such as poor technological infrastructure, economic, cultural barriers, and separation of effort could be added to this list.

Bjoernshauge (1999) believed that there are a number of obstacles for the libraries to take advantage of this development. First, there is the ever-present funding problem; entering a consortium requires initial investments in licences and ICT. Second, libraries are not prepared to cash in the savings offered by not handling the print edition of the journals. Their work procedures are still centred round the physical document and staff might not be trained in handling electronic documents. Therefore many libraries are reluctant to enter consortia agreements especially where publishers impose payments for off-consortia delivery of documents, either in electronic or paper format.

Thirdly, there will often be investments to be made in local, consortium based, central hardware set up, mounting of data, development of interfaces, administration of access and so on. However these problems are to be solved not by the single library but in co-operation between participating libraries.

\section{Some library consortia in different countries}

Ghosh (2002) reported on library consortia at an international level and included reference to the following: 
(1) ThaiLIS - a national resource-sharing system in Thailand formed from THAILINET, a network of online catalogues of academic libraries in the Bangkok region, and PULINET, a grouping of provincial academic libraries (http://uc.thailis.or.th/).

(2) China Academic Library and Information System (CALIS) - this was launched in 2000 and is a nationwide academic library consortium which links services across the provinces and cities in China (www.calis.edu.cn/calisnew/).

(3) Consortium of Academic Libraries of Catalonia (CBUC) - a consortium of the state-funded universities and the State Library of Catalonia in Spain (www.cbuc.es/).

(4) Gauteng and Environs Library Consortium (GAELIC) - the largest academic library consortium in South Africa, which is striving to achieve greater efficiency in the area of document delivery, with the objective of providing information rapidly, cost-effectively, and in accordance with users' needs and expectations (www.gaelic.ac.za/).

(5) Regional University and Science Library Advanced Network (RUSLANet) - in the Northwest of Russia, which is creating a common information space of libraries and integrating with the worldwide library information space (http://consortium.ruslan.ru/).

In Iran, there are two consortia. CONSIRAN has been actively working with the libraries of the Ministry of Science, Research, and Technology (MRST) and medical university libraries. By 2008, 57 universities are involved in this consortium and they are sharing an online access to licensed resources through networks.

In the Philippines, Fe Verzosa, 2004 reported that many consortia are still informal and voluntary in nature, borne from institutional linkages of academic libraries within a particular geographical location, and established expressly to engage mainly in interlending activities and bibliographic access. Only one, the Department of Science and Technology (DOST), Engineering and Science Education Programme (ESEP) Consortium, is a governmentsponsored consortium. It has focused on a programme of activities to upgrade the science and technology infrastructure in the country via education, in particular engineering and science education, as prescribed in its Memorandum of Agreement drawn up by DOST, and it derived its funding from a World Bank grant.

South African academic libraries have been involved in consortia activities since the 1990s and examples include:

- $\quad$ Cape Library Cooperative (CALICO), established in 1992.

- $\quad$ Gauteng and Environs Library Consortium (GAELIC), established in 1996.

- Free State Library and Information Consortium (FRELICO), established in 1996/1997.

- $\quad$ Eastern Seaboard Association of Libraries (eSAL), established in 1997.

- $\quad$ South East Academic Library System (SEALS), established in 1998.

Thomas (2004) reported that at a meeting in 1999, representatives from the previous list decided to establish the South African National Library and Information Consortium (SANLiC: www.cosalc.ac.za/). 


\section{Electronic Information for Libraries Network}

The Electronic Information for Libraries Network (known as eIFL.net) is an independent foundation that negotiates and advocates for the wide availability of electronic resources for library users in transition and developing countries. Its main focus is on negotiating affordable subscriptions to electronic journals for libraries in the education and research sectors, while supporting emerging national library consortia in member countries.

eIFL.net began in 1999 as an initiative of the Open Society Institute (OSI). In the 1990s, OSI made significant investment in library development and modernisation in the countries of its network, especially in the post socialist countries of Central and Eastern Europe as well as the former Soviet Union. In 2002, eIFL.net became an independent foundation with diversified funding registered in the Netherlands with its operational seat in Rome, Italy. Current members of eIFL.net include: Albania, Armenia, Azerbaijan, Belarus, Bosnia and Herzegovina, Bulgaria, Cambodia, Cameroon, China, Croatia, Egypt, Estonia, Ghana, Georgia, Iran, Lesotho, Jordan, Kyrgyzstan, Laos, Latvia, Lebanon, Lithuania, Macedonia, Malawi, Mali, Moldova, Mongolia, Mozambique, Nigeria, Palestine (Gaza and West Bank), Poland, Russia, Senegal, Serbia, Slovakia, Slovenia, South Africa, Sudan, Swaziland, Syria, Tajikistan, Uganda, Ukraine, Uzbekistan, Zambia and Zimbabwe.

Members express their commitment by paying a membership fee to eIFL.net and devoting their own extensive voluntary effort to managing their consortium. Sustainability of access to information is ensured by country consortia covering the cost of subscriptions to the tune of nearly $\$ 7$ million.

The mission of eIFL.net to foster access to electronic resources makes it a natural partner for the open access movement. The aim of the programme is to provide training and knowledge sharing on open access across the eIFL.net community. At the same time, eIFL.net encourages greater visibility of locally produced content in eIFL.net member countries through the establishment of institutional repositories at leading research institutions within the library consortia.

\section{Some library consortia in India}

India is a vast country with a total of 400 universities and institutes of national importance and about 18,600 colleges that provide higher education in all disciplines. The number of teachers is 3.1 million, and 7.8 million students are enrolled in higher education (Mahajan, 2005).

Academic libraries in India are also facing problems such as increasing demands and high expectations from users, budget cuts, high costs of library materials especially electronic journals, and a rise in the amount of information resources in general. It is impossible for a single library to provide access to all materials to meet their users' needs. Library consortia have been initiated in India in order to overcome these problems, and efforts to form library consortia are still in their infancy. At present, there are some networks working at national level (e.g. INFLIBNET and DELNET), some in metropolitan areas (e.g. ADINET in Ahmedabad, CALIBNET in Calcutta, and PUNENET in Pune) and others covering specific topic areas (e.g. HELNET - health libraries, and MANLIBNET management libraries). Some of these have been in existence since the 1990s - e.g. ADINET started in 1994, DELNET in 1996 and MANLIBNET in 1998. Details of four consortia in India are now described. 


\subsection{UGC: InfoNet e-journals consortium and INFLIBNET}

As stated on its web site (www.inflibnet.ac.in/) the Information and Library Network (INFLIBNET) Centre is an autonomous centre within the University Grants Commission (UGC) of India and is involved in creating the infrastructure for sharing library and information resources and services among academic and research institutions. This is being achieved via the UGC-InfoNet network, which aims to provide highspeed internet connectivity to 150 institutions in its first phase. INFLIBNET functions as a resource centre with an aim to cater for the needs of its members for resources not accessible to them either in electronic media or in print media (Koneru, 2004).

The electronic subscription initiative under UGC-Infonet is expected to trigger a remarkable increase in sharing of both print and electronic resources among university libraries through one of the gateway portals being identified. The gateway portals provide customised solutions not only to access the resources online but also access to resources of other libraries participating in the consortium. With subscribed resources accessible online in electronic format, the member libraries would have less pressure on space requirements for storing and managing print-based library resources. Moreover, all problems associated with print media such as their wear and tear, location, shelving, binding, organising, etc. would not be an issue for electronic resources.

UGC is also exploring the possibilities of alliances with publishers for adapting a consortia-based approach to e-subscriptions for journals. These journals will be available over UGC-Infonet to all the universities. Much of the new research publications are also available on the net as freeware, thereby, making quality information accessible to a wider academic scholar base spread across the country, at an affordable price. Chand and Arora (2008) provide details of the use made of e-journals between 2004-2007 by members of the INFLIBNET consortium.

\subsection{CSIR consortium}

The Council of Scientific and Industrial Research (CSIR) in India has 40 scientific laboratories involved in basic and applied research in various disciplines. Many of the laboratories have well equipped libraries, and some of them act as the main information centres for different subjects, functioning as consultant libraries at the national level. Access to e-journals through the use of state-of-the art technology is possible in many of the libraries belonging to these laboratories. Each of the laboratories has a well-established library or documentation centre that is also backed up with strategic information support from the National Institute of Science Communication and Information Resource (NISCAIR), a constituent establishment of CSIR. To augment CSIR research and development activities, NISCAIR implemented an agency for providing access to globally available e-journals to the entire scientific and technical staff of CSIR and its constituent units through a consortia approach. As a first step, NISCAIR, on behalf of CSIR, has entered into an agreement with Elsevier Science to access its 1,500 e-journals and further intends to strengthen its information resource base by subscribing e-access of more and more journals published globally. The CSIR consortium extended its access by creating appropriate agreements on a consortium basis with the other providers of e-journals. The major focus is on emerging sectors such as, biotechnology, pharmaceuticals, information/communications/entertainment (ICE) and financial services. 


\subsection{INDEST consortium}

The Ministry of Human Resource Development (MHRD) has set up the Indian National Digital Library in Science and Technology (INDEST) Consortium. Under this, the ministry provides funds required for the subscription to electronic resources for 38 core institutions including the Indian Institutes of Science (IIScs), the Indian Institutes of Technology (IITs), the National Institutes of Technology (NITs), Regional Engineering Colleges (RECs), Indian Institutes of Management (IIMs) and a few other centrally funded government institutions through the consortium. Besides that, 60 government or government-aided engineering colleges and technical departments in universities have also joined the consortium with the financial support from the All India Council for Technical Education. In addition, a total of 26 other engineering colleges and institutions have also joined the consortium on a payment basis (Saibaba and Guha, 2004). The electronic resources subscribed by the INDEST are as follows:

- Association for Computing Machinery (ACM) Digital Library.

- ASCE (American Society of Civil Engineering) journals.

- ASME (American Society of Mechanical Engineers) journals.

- Elsevier's ScienceDirect.

- IEEE/IEE Electronic Library Online (IEL).

- ProQuest Science.

- Springer Verlag’s Link.

- Indian Standards.

- Nature.

- OMPENDEX on EI Village.

- INSPEC on EI Village.

- J-Gate Custom Content for Consortia (JCCC).

- MathSciNet.

- SciFinder Scholar.

- Web of Science.

Members of the INDEST consortium generally have a networked infrastructure of computers available at their campuses. For example; the Indian Institute of Technology (IIT) Guwahati has a distributed networking arrangement spread through the length and breadth of its campus, virtually enabling all the users to access the available electronic resources. The computing infrastructure is maintained and monitored by the computer centre, which provides access via the Unix and Windows operating system, as well as Hewlett Packard workstations and Sun servers, which are used for high-end computation. A power system called "Silicon Graphics" is used for generating high-end graphics. There are also a large number of Intel based Linux servers used as computer servers, mail servers, name servers, etc. Currently the Institute has the campus-wide network on an optical fibre backbone to all the departments, offices and hostels, which terminates at the central network switch housed in the computer centre. In order to provide internet connectivity the centre has two microwave-linked leased circuits, which provides a total download-bandwidth of 3Mbps, of which 2Mbps is a leased line from ERNET and 1Mbps is a leased line 
from the Software Technology Park of India, Guwahati. The library web page provides links to all subscribed online journals. In addition, it provides links to all e-resources available through the INDEST Consortium. The library users are provided with a secured and hassle-free log-on procedure. The users can access all the e-resources through the Institute's IP Ranges. This arrangement helps the users to access the resources immediately and provides a foolproof system of security. They are free from memorising user ID, password, publishers's URLs, etc. (Saibaba and Guha, 2004).

INDEST offers the best possible price advantage at an average of 80 per cent plus through its pricing agreements with e-resource providers. Furthermore, the consortium provides technical assistance and inhouse training for optimal usage of resources subscribed. Likewise, it endeavours to identify other e-resources relevant to the institutions and enables access under best possible subscription prices and license terms. With continuous monitoring of international developments in this domain and liaison with agencies like ICOLC, INDEST tries to bring best possible consortium-based e-information services to its members (Koneru, 2004).

Finally, INDEST is an open-ended proposition, and welcomes other institutions with the similar area of interest and who can join for sharing benefits. The INDEST consortium is the most ambitious initiative taken up so far in India in the area of engineering and technology disciplines.

\subsection{FORSA consortium}

The Indian Astrophysics Consortium called Forum for Resource Sharing in Astronomy (FORSA) is a typical example of a homogeneous group of members wherein the libraries have a common area of interest and establishing the consortium is slightly easier than in a heterogeneous type of members. The FORSA consortium consists of five members who joined together for negotiating licensing for astronomy journals and identified a subscription agent as a supplier of journals. Subscriptions for both print and electronic format are paid through their supplier. The agreement was originally meant for only astronomy journals, published by a particular publisher.

However, consortium members also now share the licence fee to enable e-access to the

journal Nature (Kumbar, 2004).

Several other organisations such as the Indian Council of Agricultural Research (ICAR), State Agricultural Universities, Indian Space Research Organisation (ISRO), Defence Research and Development Organisation (DRDO), AICTE and some other individual groups of institutions have started working to form different consortia. Francis (2005) observes that library consortia in India is a separate effort and the present system of formation and maintenance of different library consortia for each group of academic and research institutions is unscientific. He suggested that instead of establishing separate library consortia by different groups of educational and research institutions, it is better to form one consortium for all educational and government research institutions with countrywide access to all online journals and databases.

\section{Concluding remarks}

There are many advantages for libraries if they buy their materials, especially electronic resources, through consortia, although there are some disadvantages too. Consortia, in general, are tailored to meet the unique needs of 
their membership. Consortia purchasing projects have become a basic tool that expand collections and support cooperative technological development for libraries. Library consortia are considered as a coalition between libraries, publishers and vendors. They often provide a reasonable price in a win-win situation for all stakeholders. Thus, libraries have increasingly turned to consortia as a way of brokering better prices and rendering rapid and efficient services to information seekers. However, library consortia are facing new challenges, such as increasing expectations and a static budget, fair use, archiving of information, pricing strategies, measures of effectiveness and licensing e-resources.

It is clear that the creation of the web and networks brought many possibilities for integrating consortia activities both in developed and developing countries. The library consortia are shifting from a peripheral and limited position of resource sharing to an integrated system-wide resource sharing in recent years in the West.

With the help of networks and the internet, libraries in developing countries have also begun to create consortia at national, regional and international level to share their resources and expand access to print and electronic collections and develop new services to meet their customers' needs. However, some barriers such as poor technological and communication infrastructure, inadequate finances, culture and context, attitude toward consortia and multiple efforts are reported to be limitations of consortia activities in developing countries.

While India has been active in consortia activities among developing nations, due to limitations it is hard to find a successful programme that could be used as a benchmark to replicate in other libraries. Francis reported that establishment and maintenance of a separate library consortium for each group of government and governmentsupported institutions in India has led to the duplication of efforts and additional investment.

Another issue in Indian library consortia is the fact that almost all the major consortia in India are currently concentrating only on e-resource sharing; therefore the need of the hour is to explore the other areas for collaboration in order to improve the overall situation of libraries in terms of resources and services. India is not seen as a current member of international library consortia namely, eIFL.net. The eIFL.net is created to help and support library consortia in transition and developing countries. Therefore, membership of e.IFL.net can be useful for India and other developing countries as well.

It can be concluded from the previous discussion that libraries in developing countries need to battle with the problems that prevent a successful consortia effort, because the advantages of consortia, especially for sharing electronic resources, are much more for these libraries. Membership of international consortia can be recommended for all developing countries as it brings them all together to redefine and re-engineer their consortia efforts. 


\section{References}

Bjoernshauge, L. (1999), “Consortia licensing: implications for digital collection development”, Inspel, Vol. 33 No. 2, pp. 11621, available at: www.fh-potsdam.de/,IFLA/INSPEL/99-2bjol.pdf

Chand, P. and Arora, J. (2008), “Access to scholarly communication in higher education in India: trends in usage statistics via INFLIBNET”, Program: Electronic Library and Information Systems, Vol. 42 No. 4, pp. 382-90.

Fe Verzosa, A.M. (2004), "Library consortia and cooperation in this digital age: an overview of the Philippine experience", Proceedings of the Library Management in the Twenty-first Century, Quezon City (Philippines), 29-30 March, available at: http://eprints.rclis.org/archive/00012908/

Francis, A.T. (2005), "Library consortia model for country wide access of electronic journals and databases”, in Murthy, T.A.V. (Ed.), Proceedings of the International Conference on Multilingual Computing and Information Management in a Networked Digital Environment, Cochin (India).

Ghosh, M. (2002), “Indian academic library consortia (IALC): a proposal for electronic resource sharing”, Proceedings of the Crimea-2002 International Conference: Russian National Public, Library for Science and Technology, Sudak, Vol. 2, pp. 594600, available at: http://eprints.rclis.org/archive/00007292/Helmer, J.J. (2004), “Consortial collaboration: a perspective from the US”, 6th E-ICOLC (International Coalition of Library Consortia in Europe), Barcelona, available at: http://eprints.rclis.org/archive/00002957/

Koneru, I. (2004), "E-information service through consortia”, in Rao, N.L. (Ed.), Proceedings of the National Seminar on Library Consortia, 22-23 March, Hyderabad, India, pp. 27-37.

Kumbar, M.F. (2004), “Consortia for management of college libraries in the e-publishing era: a proposal”, Proceedings of the 6th MANLIBNET National Convention, Janakpuri, New Delhi, available at: http://eprints.rclis.org/archive/00003978/

Mahajan, P. (2005), “Academic libraries in India: a present-day scenario”, Library Philosophy and Practice, Vol. 8 No. 1, pp.1-4.

Nfila, R.B. and Darko-Ampem, K. (2002), "Developments in academic library consortia from the 1960s through to 2000: a review of the literature”, Library Management, Vol. 23 Nos 4/5, pp. 203-12.

Pandian, P.M., Jambhekar, A. and Karisiddappa, C.R. (2002), “IIM digital library system: consortia-based approach”, The Electronic Library, Vol. 20 No. 3, pp. 211-14.

Payne, L. (1998), “The Washington research library consortium: a real organization for a virtual library”, Information Technology and Libraries, Vol. 17 No. 1, pp. 13-17.

Saibaba, B. and Guha, T.M. (2004), “Access to e-journals through INDEST consortium at IIT”, in Rao, N.L. and Guha, T.M. (Eds), Proceedings of the National Seminar on Library Consortia, 22-23 March, Hyderabad, pp. 285-91.

Singh, S. and Singh, S. (2004), "Need for joining library consortia: a study of Vikram University Library”, in Rao, N.L. and Murthy, T. (Eds), Proceedings of National Seminar on Library Consortia, 22-23 March, Hyderabad, India, pp. 267-9.

Thomas, G. (2004), "South African academic library consortia: creating value together", Proceedings of the 6th E-ICOLC (International Coalition of Library Consortia in Europe), Barcelona, 28-30 October, available at: www.cbuc.es/icolc04bcn/presentations/Thomas.ppt

All URLs were checked on 12 September 2008.

Corresponding author: Golnessa Galyani Moghaddam can be contacted at: g_galyani@yahoo.com 